\title{
TOWARDS A METHODOLOGY FOR USE OF SONIC AND ULTRASONIC TESTS IN EARTHEN MATERIALS
}

\author{
RACHEL MARTINI ${ }^{1}{ }^{*}$, JOSÉ DANIEL RODRÍGUEZ MARISCAL ${ }^{2}$, JORGE \\ CARVALHO $^{3}$, MARIO SOLÍS ${ }^{4}$, AND HUMBERTO VARUM ${ }^{5}$ \\ ${ }^{1}$ CONSTRUCT-LESE - Faculty of Engineering (FEUP) \\ University of Porto, Portugal \\ e-mail: martini.rachel@fe.up.pt (*corresponding author) \\ ${ }^{2}$ Escuela Técnica Superior de Ingeniería \\ University of Seville, Spain \\ e-mail: josedrm@us.es \\ ${ }^{3}$ DEM/CERENA - Faculty of Engineering (FEUP) \\ University of Porto, Portugal \\ e-mail: jorcarv@fe.up.pt \\ ${ }^{4}$ Escuela Técnica Superior de Ingeniería \\ University of Seville, Spain \\ e-mail:msolis@us.es \\ ${ }^{5}$ CONSTRUCT-LESE - Faculty of Engineering (FEUP) \\ University of Porto, Portugal \\ e-mail: hvarum@,fe.up.pt
}

Keywords: wave velocity, nondestructive test, mechanical characterization and earthen materials

\begin{abstract}
In many regions around the world, earth has been used through history as a traditional building material. Nowadays, there is a significant revival of its use due to its ecological value and architectural performance. However, there is still a significant lack of knowledge about its actual mechanical properties and behavior. This work aims at the development of consistent methodologies for the characterization of this building material based on non-destructive tests, NDT's. Ultrasonic and sonic tests on prismatic rammed earth specimens and adobe bricks were carried out. The paper presents an optimized method for estimating $S$-waves and $P$-waves based on direct and indirect non-conventional sonic testing methods. Finally, the paper discusses methodological issues for estimating the earthen material properties through the propagation velocity of sonic waves.
\end{abstract}




\section{INTRODUCTION}

The careful evaluation of earthen constructions in order to make the most of the existing building is imperative prior to restoration and rehabilitation. A good approach is to use nondestructive testing methods, NDT's, providing the necessary characteristics of the materials without causing damage. This paper presents a new methodology based on the use of sonic tests (ST) and ultrasonic tests (UST) for prismatic rammed earth specimens and adobe bricks.

The discussion allowed having a better perception of the test limitations and potentialities, as well as on the difficulties and peculiarities of these techniques. The application of nondestructive tests on earthen materials can be frustrating in that the interpretation of results is often not straightforward and may be potentially misleading. This is partly because it is a heterogeneous composite material and it presents non-linear and non-isotropic behavior under mechanical destructive tests $[1,2]$. It should also be noted that these techniques come mostly from other fields of research, namely geophysical exploration, so proper calibration is required [3-6].

The wave propagation time in ST and UST is the time lapse between the generation of a wave and the respective arrival time at the receiver location. The arrival time and traveling distances of the waves are often not accurately recognizable even when it does correspond to a first arrival as well as the corresponding type of wave. The study involving determining the velocity of waves has been much discussed in the last 50 years, because it allows deriving several properties of the materials namely the elastic moduli [7]. In the present research work,

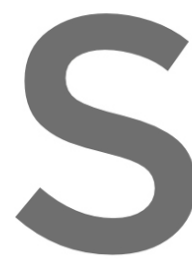
ST and UST are being applied conventionally and non-conventionally assembled prismatic results are analyzed and

The results provide q and mechanical behavio and particle size distribution of a construction
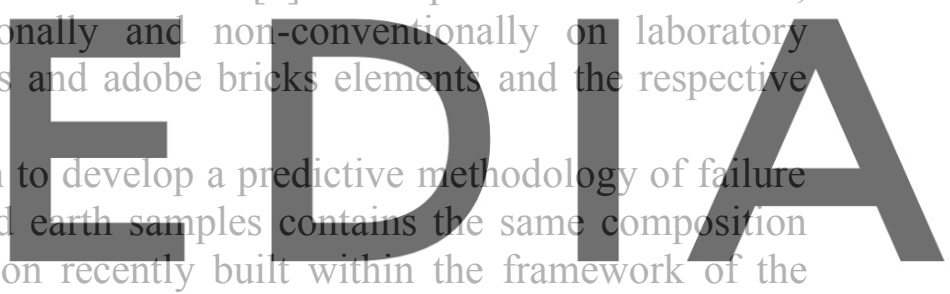
Eramus+ Project "LearnBION - Learn Building Impact Zero Network (2015-2028) 2015-1-

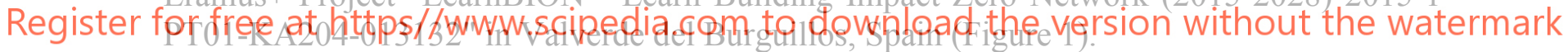

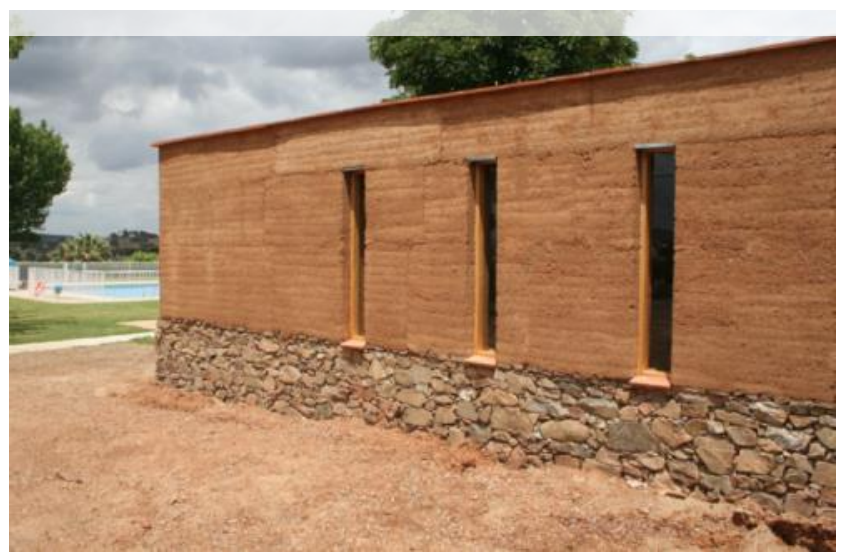

Figure 1: Rammed earth building in Valverde del Burguillos, Spain. 


\section{SONIC AND ULTRASONIC TEST THEORY}

Using direct and indirect sonic tests, it is possible to obtain propagation velocities of $\mathrm{P}, \mathrm{R}$ and $\mathrm{S}$ waves and then estimate values of Poisson's ratio, Young's modulus and shear modulus.

The ST may operate using the direct, refraction or reflection propagation paths of the emitted signals, the receiver(s) being positioned in different configurations in relation to the shot-point, SP. The energy may propagate from the point where it is generated namely as compressive P-waves, surface R-waves and shear S-waves. P-waves being the fastest are often more easily and accurately identified using the ST direct configuration, Figure 2, a).

The waves are generated by the impact of a hammer instrumented with a piezoelectric sensor that records the force of the impact. The generated signal is received by piezoelectric accelerometer transducers used as sensors (receivers) in preset positions and orientations. The acquisition of the readings was performed using a data acquisition board, connected via USB to a laptop computer with software specifically developed in LabVIEW. The analysis of the hammer and accelerometers recorded signals, to identify the initial point of the impact of the hammer and the point of arrival of the waves [8-11].

The frequency and amount of energy of the thrust force are governed by the characteristics of the hammer, the impacted material as well as the impact force. The hammer mass, tip hardness and impact force determine the amplitude and duration of the pulse, where harder tips generate shorter duration signals and broader frequency bandwidths. The material vibrations related to the propagation of the sonic waves are measured as varying voltages by

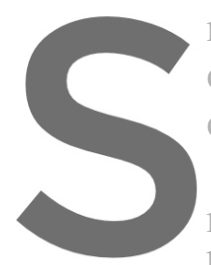
means of transducers such as carried out, the alurni consequently broader fr

To carry out ST, hroe different con relative position between the emitter and the be studied (P, S or R): direct, semi-direct and indirect test configurations (Figure 2).

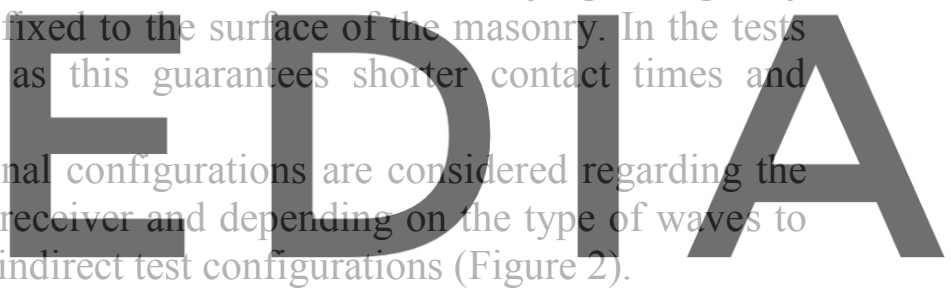

Register for free at https//www.scipedia.com to download the version without the watermark

(a)

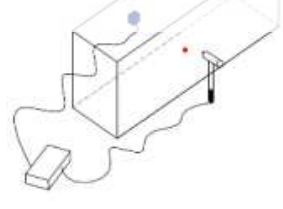

(b)

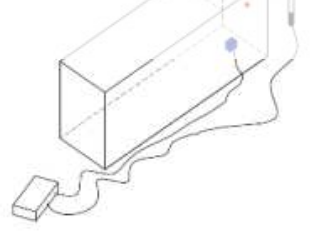

(c)

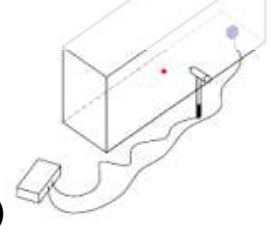

Figure 2: Sonic test (a) direct, (b) semi-direct and (c) indirect.

The direct test assumes a linear wave direct transmission through the thickness of the element to be tested, being the shot-point and receiver in opposite sides of the element, which aims to determine P-waves velocity. The velocity of the P-waves is dependent on the quality and consistency/density of the section tested, i.e. it is directly related to the mechanical properties of the material.

In the semi-direct test, the shot-point and receiver are in adjacent faces of the element.

In the indirect test, the shot-point and receiver are on the same face of the element and it is conventionally assumed a linear wave direct transmission, along the surface of the tested 
element. The waves obtained by this configuration are conventionally assumed to be those that cross mainly the outermost part of the element, so the quality and consistency of the most superficial layer of the material are considered to mainly govern the acquired wave velocities.

The identification of the waves depends on the intrinsic characteristics of each type and the type of configuration test to be performed. In indirect configurations, $\mathrm{P}$-waves are not always clearly identified despite being the fastest (first arrival) waves, having comparatively with Rwaves lower energy content. Note that despite their higher energy content, R-waves are not always readily detectable, being the acquired signal the result of different contributes, namely $\mathrm{P}$-waves and S-waves.

According to the literature, [12-16], UST is more accurate than ST to calculate wave propagation velocities when using the direct configuration. According to [17], this method is widely used and consolidated for concrete samples.

\section{METHODOL OGV}

\subsection{Materials and geometry}

An adobe specimen (Figure 3) is a brick made of earth, sand and fiber molded and sundried. The earth composition determines the physical behavior, cohesion and mechanical properties being influenced by the proportion of sand, silty clay and clay presented in the earth. Generally, the content of silty clay is between $20 \%$ and $40 \%$, the content of clay is between $10 \%$ and $25 \%$ [18]. Furthermore, size and length of fiber are determinant parameters,
their modification affects mechanicalpropertics [19]. The adobe tested is composed of natural
fibers (straw) of $5-10 \mathrm{~cm}$ length. The adobe bricks presented the following nomina
dimensions: [320x160x80] mm in order to comply with the Peruvian recomnendations of
NTE0.80 [20]. The selected soil was collected from the riverbank of the Guadalquivir River
in Seville (Spain).

The rammed earth is a clayey soil (earth) compacted into a formwork. That soil has

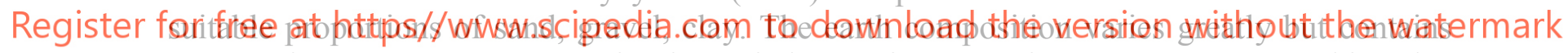
no organic component. Compaction is carried out using an optimum water content; this value can be obtained by Proctor compaction test. The rammed earth is made of layers of earth. After compaction, the thickness of each layer should be comprised of between 8 and $10 \mathrm{~cm}$ [1].

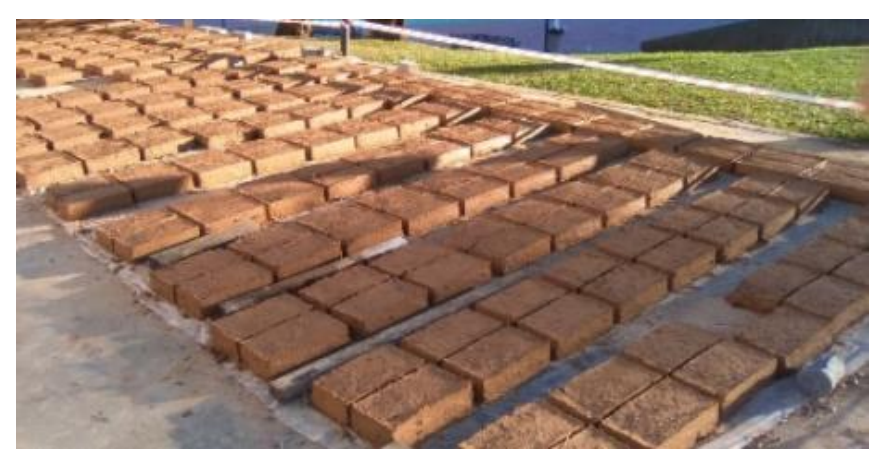

Figure 3: Adobe specimens. 
Two size specimens of rammed earth (Figure 4) were produced with the following nominal

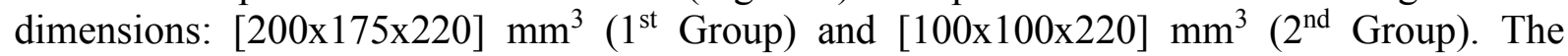
specimens were produced by molding the soil mixture preparation into a wood framework. The manufacturing process was carried out following two different compaction methodologies: manual compaction for specimens of the $1^{\text {st }}$ Group and automatic compaction for $2^{\text {nd }}$ Group. The selected soil was collected from the local quarry of Valverde del Burguillos in Badajoz (Spain). The specimens were stored in a stable laboratory environment for approximately 100 days (approximately $24^{\circ} \mathrm{C}$ and $50 \%$ relative humidity) until the hygrometric equilibrium was reached. The moisture content of specimens was not measured at NDT, therefore the eventual influence of this parameter in the propagation velocities was not evaluated.

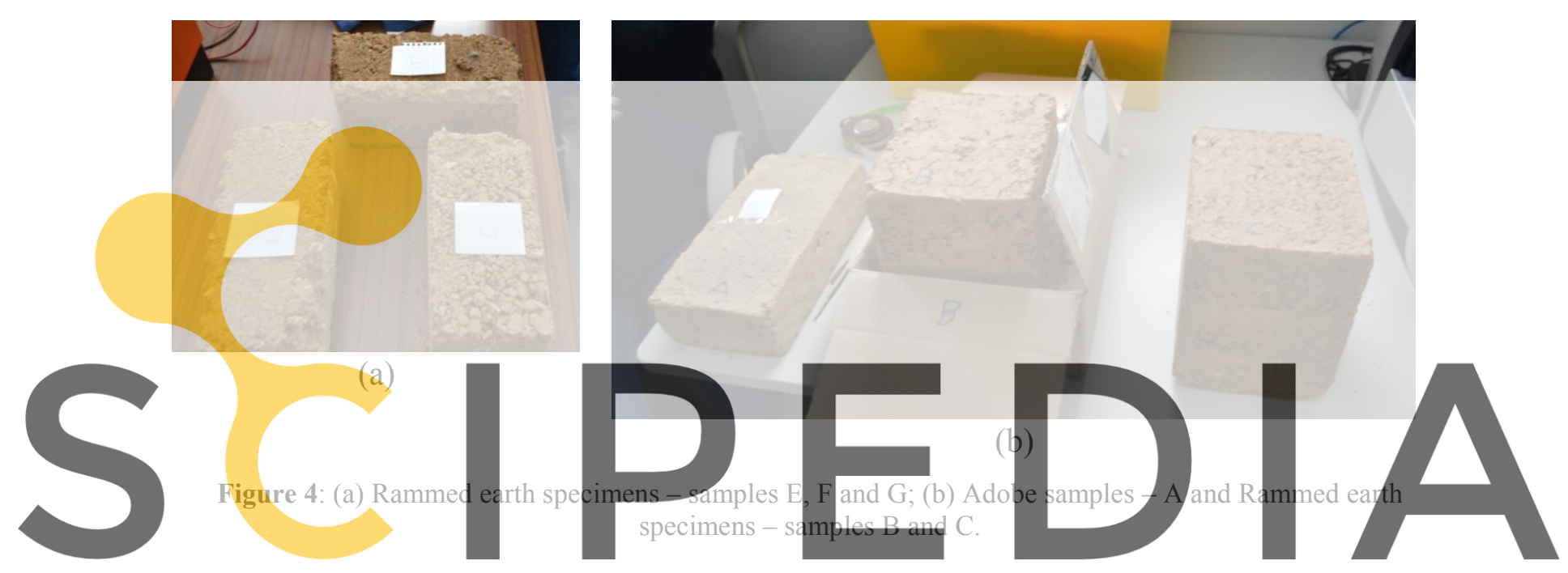

Register for free list of fpecimens tested and their dimensions are summarized in Table 1 thout the watermark Table 1: Specimens tested

\begin{tabular}{cccccc}
\hline Code & Samples & Dimensions (mm) & Direct ST & Indirect ST & $\begin{array}{c}\text { Direct } \\
\text { US }\end{array}$ \\
\hline Adobe brick & Adobe brick - A & $322 \times 170 \times 80$ & $\mathrm{X}$ & $\mathrm{X}$ & $\mathrm{X}$ \\
\hline \multirow{2}{*}{$1^{\text {st }}$ Group } & Rammed earth - B & $200 \times 175 \times 245$ & $\mathrm{X}$ & $\mathrm{X}$ & $\mathrm{X}$ \\
\cline { 2 - 6 } & Rammed earth - C & $200 \times 175 \times 235$ & & $\mathrm{X}$ & $\mathrm{X}$ \\
\cline { 2 - 6 } & Rammed earth - D & $200 \times 175 \times 218$ & $\mathrm{X}$ & $\mathrm{X}$ & $\mathrm{X}$ \\
\hline \multirow{2}{*}{$2^{\text {nd }}$ Group } & Rammed earth - E & $105 \times 95 \times 222$ & & & $\mathrm{X}$ \\
\cline { 2 - 6 } & Rammed earth - F & $105 \times 105 \times 222$ & & & $\mathrm{X}$ \\
\cline { 2 - 6 } & Rammed earth - G & $100 \times 105 \times 222$ & $\mathrm{X}$ & & \\
\hline
\end{tabular}

\subsection{Test set-up and equipment}

Two ST sequences were performed, using direct and indirect configurations. The indirect configuration was developed using the conventional and a non-conventional approach, socalled 'key methodology' (Figure 5), aiming at improving the generation and estimation of Swaves velocity. An ordinary key was used to provide a different impact direction that 
paralleled the reception axis of the accelerometer. The rammed earth specimens were tested in two different directions: the compaction (hereafter $\mathrm{C}$ ) and non-compaction (hereafter NC) directions during the manufacturing process.

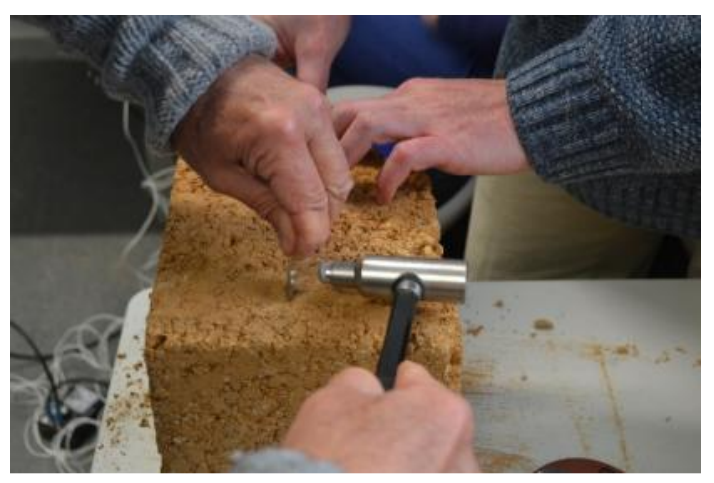

Figure 5: "Key" methodology.

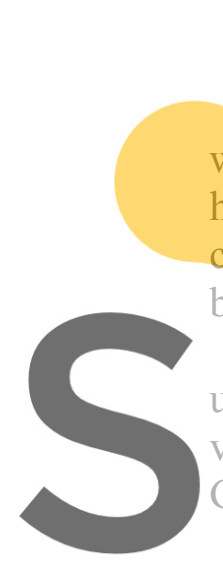

\section{The tests were}

conducted following some recommendations of international standards, which were developed for other materials (rocks and concrete) [21-23]. An instrumented hammer and two accelerometers were used for the sonic tests. The signal conditioning has carried out by a National Instrument device; the data acquisition and analysis were performed by software LabView designed, from LESE (FEUP), for this proposal

\section{The UST were also}

ultrasonic equipment

value of transmitter

Geotechnical Laborator

The procedure step
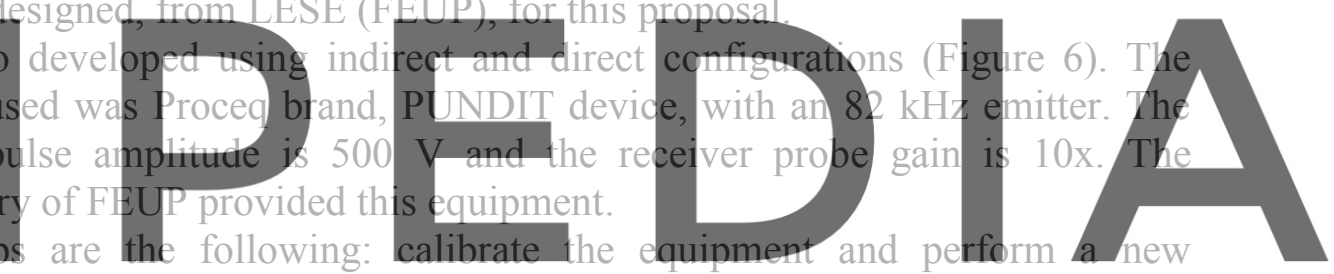

calibration whenever atmospheric conditions change, select the location of the transducers,

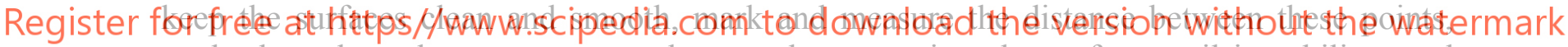
apply the gel conductor, compress the transducers against the surface until it stabilizes and perform the reading following signal generation.

The eventual gel conductor effects in the ultrasound velocities have not been included in the present experimental campaign. The application of the gel conductor can affect the contact surface quality between transducers and specimen. The gel application repeatedly on earthen materials can produce softening on the external surface and loose sand and gravel, worsening the transducer coupling.

This equipment consists of a central unit, which includes a pulse generator with frequencies between 20 and $150 \mathrm{kHz}$, an emitter transducer, a receiver transducer, an amplifier and a device for measuring the time between sending and receiving the pulse. Some of these tests were performed for comparison with the ST results.

The indirect configuration for UST was applied in the specimens (Figure 6a). However, it has not been possible to detect, confidently enough, R-waves. The close proximity between emitter-receiver and the used frequencies may be the cause. So, R-waves travel-times have not been included in the investigation. 

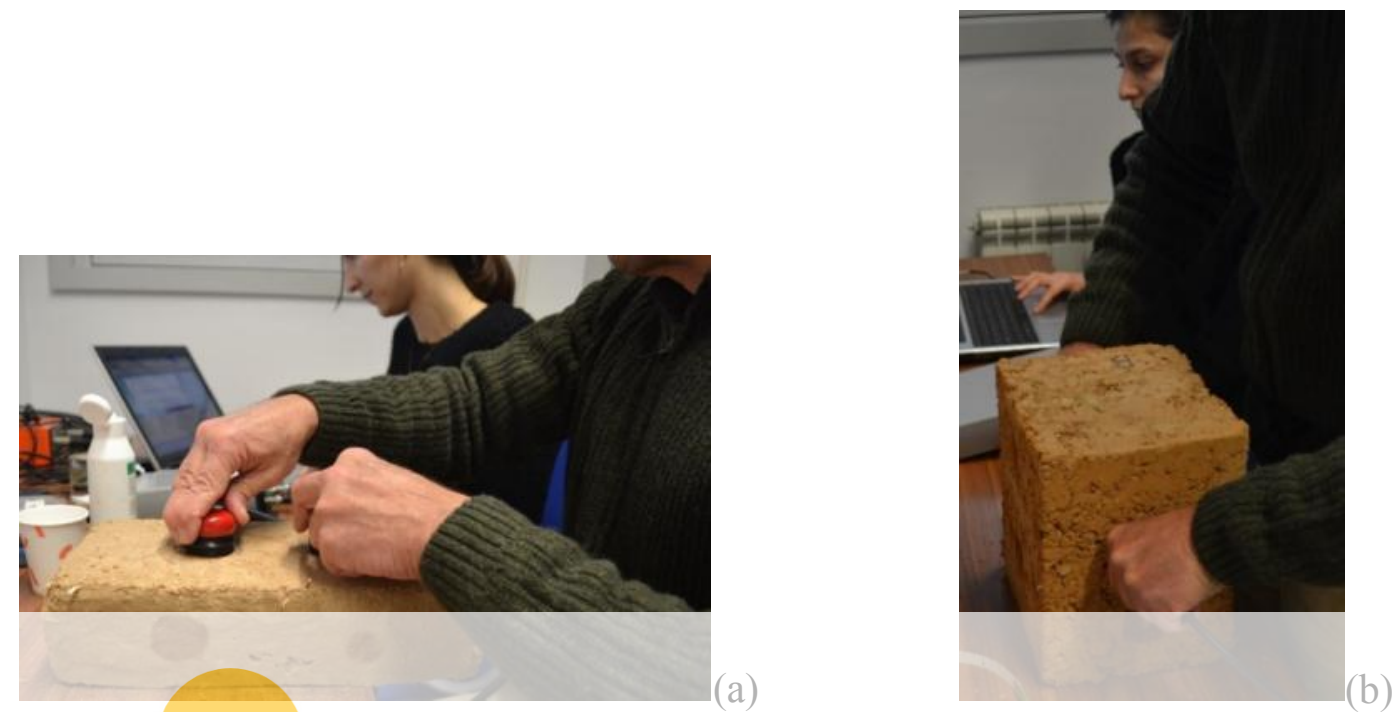

Figure 6: (a) indirect UST and (b) direct UST

\section{RESULTS AND ANALYSIS}

This section summarizes the results obtained with the ST and UST on all samples

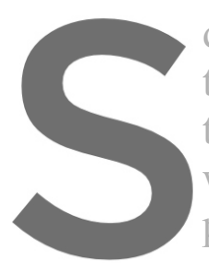
described above. These results ar the identified wave type ( $P$ on $S$ the bottom and top edg whiskers extend to the most extreme data point plotted individually using the

In these preliminary results, the P-wav
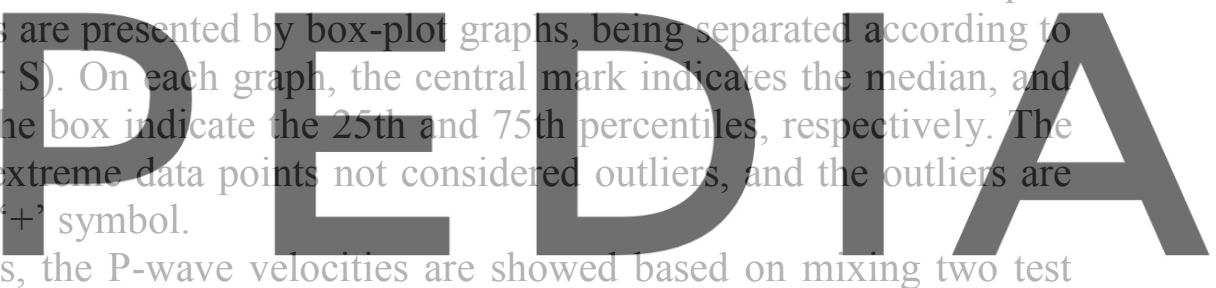

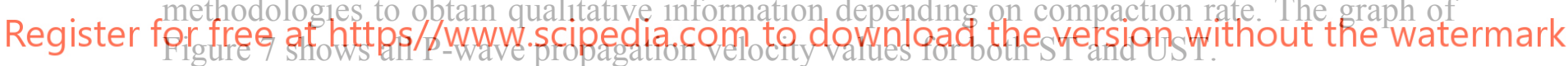

Variations of the compaction methodologies of samples influence the results. Sample A

(adobe) presented a different value from the other samples, this was expected due to its differentiated composition. Samples B, C, D, E, F and G are composed of the same material (rammed earth) but have different dimensions and compaction methodologies. First group with samples B, C and D had approximated median velocity values to each other. The second group of samples $\mathrm{E}, \mathrm{F}$ and $\mathrm{G}$ presents different median velocity values. This was expected since they have different compaction methodologies between these two groups, therefore the internal structure and particle distribution can be affected by compaction process.

The graph in Figure 8 presents the results of S-wave propagation velocity. These are samples B and D, both are of rammed earth and with the same dimensions. These samples present approximated median velocity values. There are no difference between UST or ST, and Compaction (C) or Non-Compaction (NC) direction as shown in Figure 7 and Figure 8. 


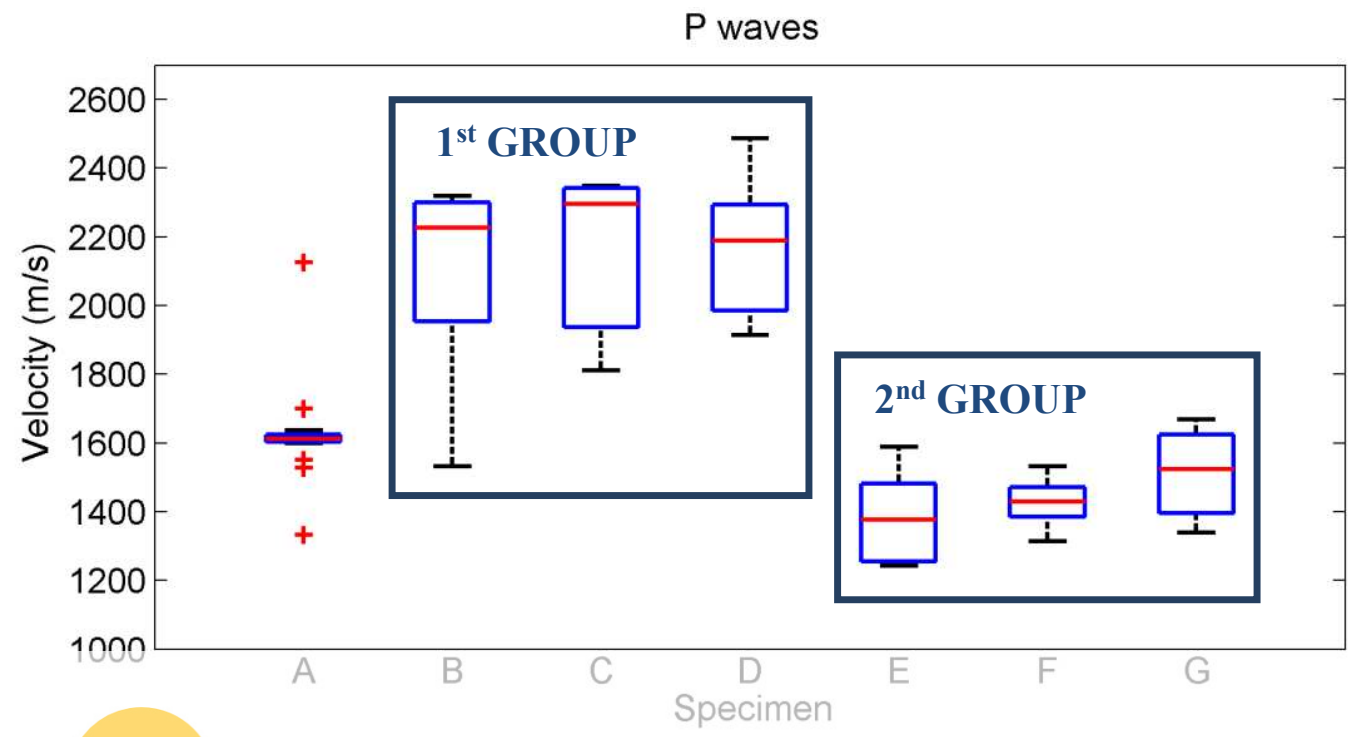

Figure 7: P-waves velocity with UST and ST, direct configuration.

\section{S waves}

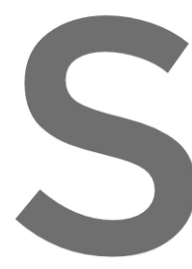

\section{0}
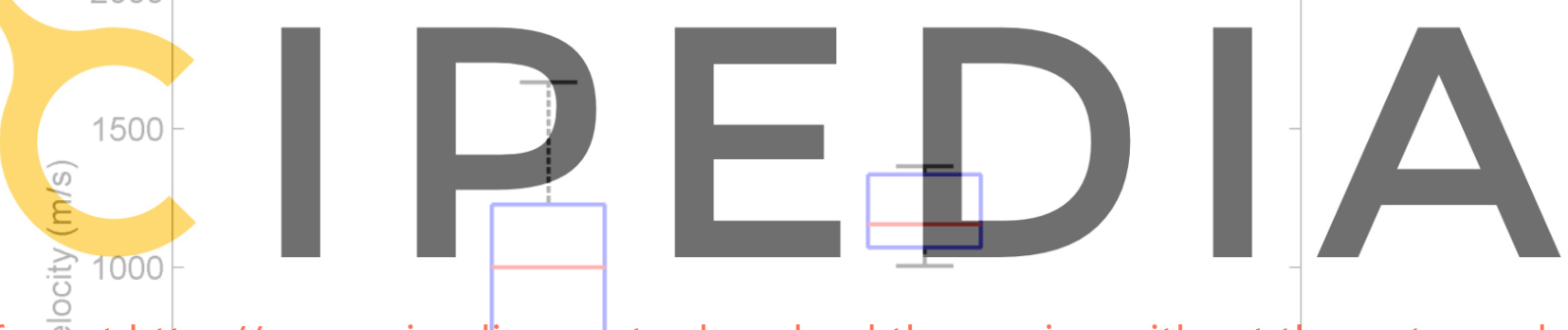

Register for free at https//www.scipedia.com to download the version without the watermark

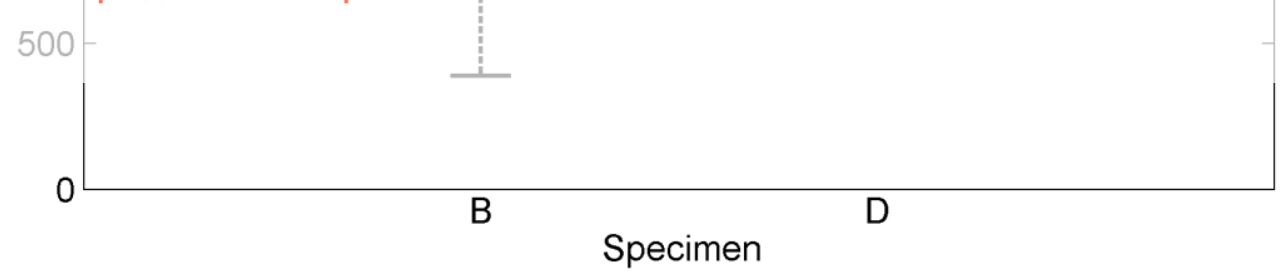

Figure 8: S-waves velocity, ST - "key" methodology.

The graph in Figure 9 shows all P-wave propagation velocity values for UST only. As in Figure 7, variations in compaction process influence the results. Sample A (adobe) presented a different value from the other samples. The first group with samples B, C and D had approximate average velocity values. The second group of samples E, F and G have different but also approximate median velocity values, which was expected due to the different compaction methodologies between these two groups. There is no difference between $\mathrm{C}$ and NC directions. 


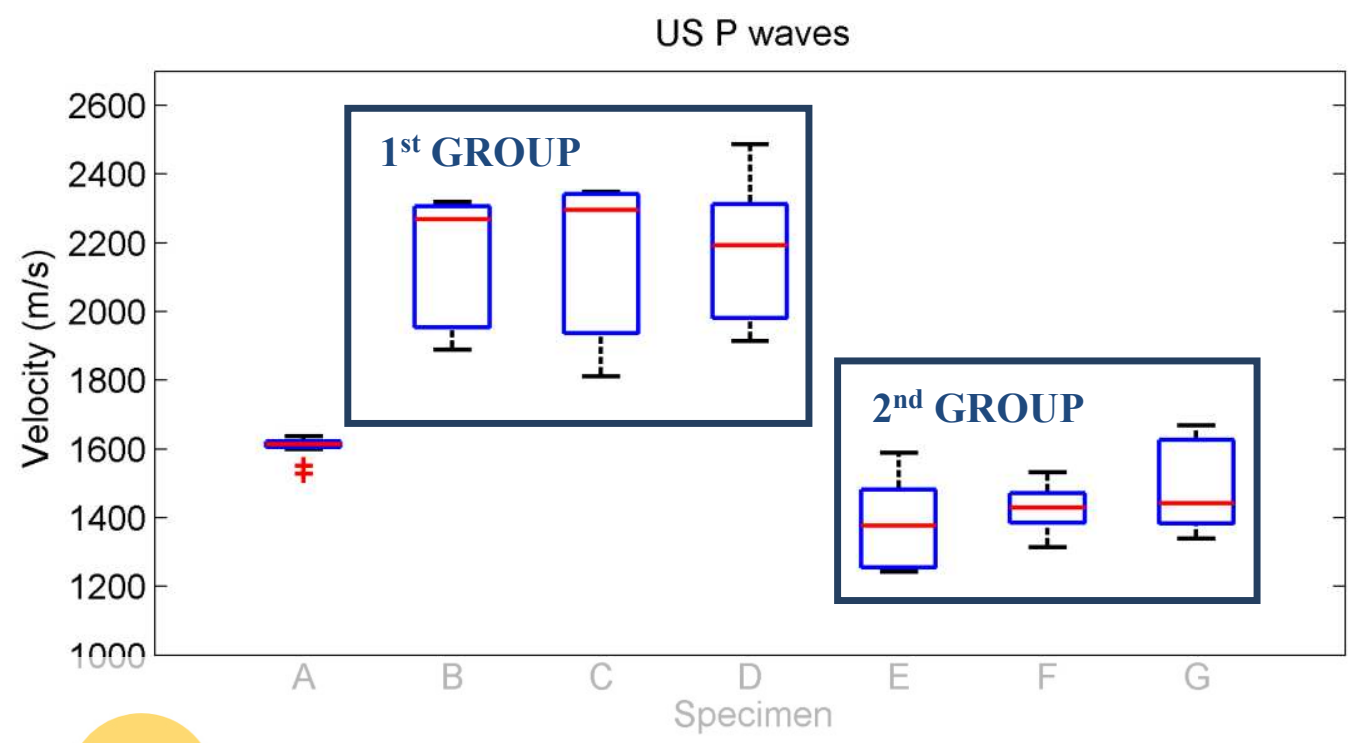

Figure 9: P-waves velocity, UST, direct configuration.

The graph in Figure 10 presents the P-wave propagation velocity results obtained by the UST, as well as indicating the $\mathrm{C}$ and $\mathrm{NC}$ variations. As in the previous results, the samples were divided into two groups according to their geometric characteristics. The second group has lower P-wave propagation velocity values than the first group, due to its compaction
method. In this graph it is also possible to see, in the first group, the influence of the effect that the compaction samples have, sine they have lower velocity values.

US P waves - Compaction Direction VS Non-Compaction Direction

Register for free atdottps//www.scipedia.com to download the version without the watermark

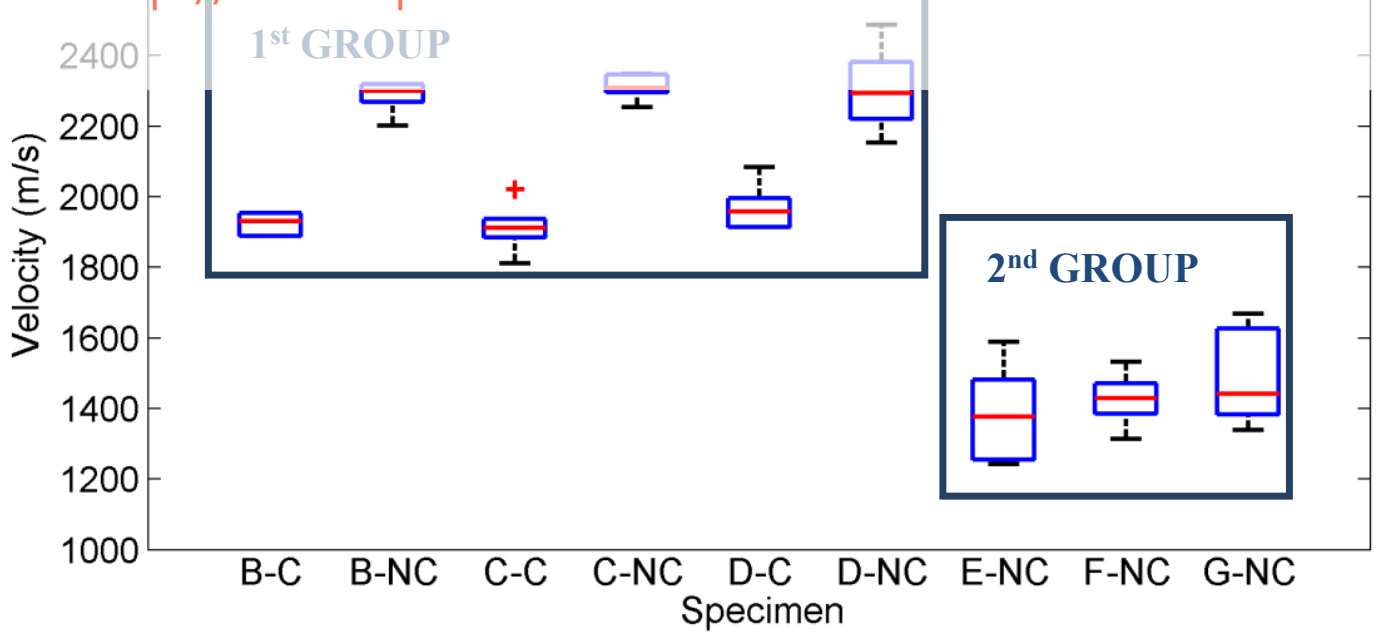

Figure 10: P-waves velocity, UST. 


\section{CONCLUSIONS}

This paper presents an exploratory study that used the well-known ST and UST in earthen materials. The results show a high degree of scattering due to the heterogeneity and anisotropy of the tested material.

These methodologies allowed to obtain some preliminary reference $\mathrm{P}$ and S-waves velocity values for this material used in a rammed earth building (Valverde del Burguillos, Spain).

Currently, several non-destructive tests on specimens of different size are being carried out to estimate mechanical properties and obtain correlations with those obtained from compression tests.

Ongoing work is also focused on in-situ investigating the wave propagation velocities of the building walls recently constructed (Valverde del Burguillos, Spain).

Acknowledgements. This work was supported by Junta de Andalucia (Consejería de Economía y Conocimiento) through research project US-126491, the Spanish Ministry of Science, Innovation and Universities (Ministerio de Ciencia, Innovación y Universidades) through research project PID2019-109622RB-C21 and European Commission UE through Eramus+ Programme - Student Mobility for Traineeships. This work reports research partially financed by the UID/ECI/04708/2019- CONSTRUCT - Instituto de I\&D em Estruturas e Construções funded by national funds through the FCT/MCTES (PIDDAC). The authors would like to thank CEFET-Mig (Centro Federal de Educaçã
Brasil), CAPES (Coordenação de Aperfeiçoannento de Pessoa financial support.
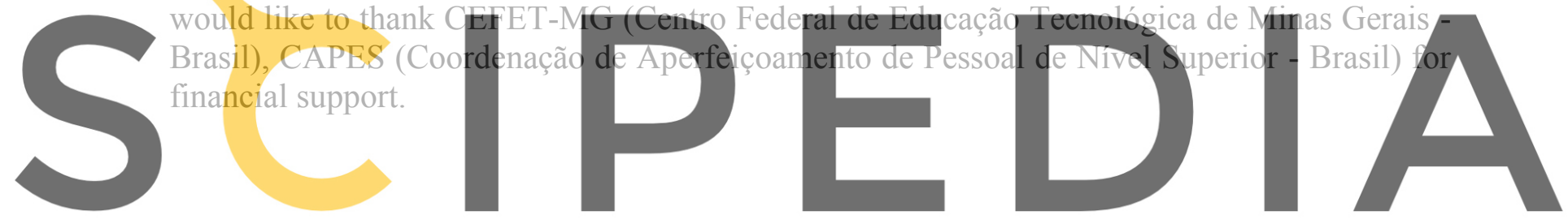

REFERENCES

Register for free at https//www.scipedia.com to download the version without the watermark

1. Bui Q-B, Morel J-C (2009) Assessing the anisotropy of rammed earth. Constr Build

Miater 23:3005-3011. https://doi.org/10.1016/j.conbuildmat.2009.04.011

2. Bui T-T, Bui Q-B, Limam A, Maximilien S (2014) Failure of rammed earth walls:

From observations to quantifications. Constr Build Mater 51:295-302.

https://doi.org/10.1016/j.conbuildmat.2013.10.053

3. Binda L, Lenzi G, Saisi A (1998) NDE of masonry structures: use of radar tests for the characterisation of stone masonries. NDT E Int 31:411-419.

https://doi.org/10.1016/S0963-8695(98)00039-5

4. Binda L, Saisi A (2002) State of the art of research on historic structures in Italy. Dep Struct Eng Politec Milan, Italy

5. Anzani A, Binda L, Lualdi M, et al (2006) Use of Sonic and GPR Tests to Control the Effectiveness of Grout Injections of Stone Masonry. ECNDT 3:1-7

6. Miranda L, Cantini L, Guedes J, et al (2013) Applications of Sonic Tests to Masonry Elements: Influence of Joints on the Propagation Velocity of Elastic Waves. J Mater Civ Eng 25:667-682. https://doi.org/10.1061/(ASCE)MT.1943-5533.0000547

7. Mishina H, Asakura T (1975) Zero-crossing probability density of Doppler beat signals 
in the wave-period measuring system. Appl Phys 8:179-182.

https://doi.org/10.1007/BF00896035

8. Guimarães M (2009) Caracterização de paredes de alvenaria de pedra por técnica sònica. Faculdade de Engenharia da Universidade do Porto

9. Miranda LFB (2011) Ensaios acústicos e de macacos planos em alvenarias resistentes. Faculdade de Engenharia da Universidade do Porto

10. Maia I da S (2016) Caracterização de alvenaria de granito com recurso a ensaios de propagação sónica e de macacos planos. Faculdade de Engenharia da Universidade do Porto

11. Matos SRPR (2016) Caracterização de estruturas de alvenaria de pedra por recurso aos métodos do georadar, resistividade eléctrica e ensaios sónicos - Tese de mestrado. Instituto Superior de Engenharia do Porto

12. Finas M, Ali H, Cascante G, Vanheeghe P (2016) Automatic shear wave velocity estimation in bender element testing. Geotech Test J 39:557-567. https://doi.org/10.1520/GTJ20140197

13. Wu Y, Cascante G, West JS, Pandey MD (2015) Ultrasonic Testing of a Grouted Steel Tank for Debonding Conditions. J Environ Eng Geophys 20:31-46. https://doi.org/10.2113/JEEG20.1.31

14. Wu YC, Cascante G, Pandey MD (2014) Condition assessment of longitudinal pavement joints using ultrasonic surface waves. Can J Civ Eng 41:1019-1028. https://doi.org/10.1139/cjce-2013-0301

15. Tallavó F, Cascante G, Pandey MD (2009) New methodology for source characterization in pulse velocity testing. Geotech Test J 32:16. https://doi.org/10.1520/GTJ101689

16. Cascante G, Najjaran H, Crespi P (2008) Novel Methodology for Nondestructive Evaluation of Brick Walls: Fuzzy Logic Analysis of MASW Tests. J Infrastruct Syst 14:117-128. https://doi.org/10.1061/(ASCE)1076-0342(2008)14:2(117)

17. Júlio ES (2005) Avaliação in situ da resistência à compressão do betão. In: $2^{\circ}$ Seminário - A intervenção no patrimônio. Práticas de conservação e reabilitação. pp $41-52$

18. Wu F, Li G, Li H-N, Jia J-Q (2012) Strength and stress-strain characteristics of traditional adobe block and masonry. Mater Struct 46:1449-1457. https://doi.org/10.1617/s11527-012-9987-y

19. Parisi F, Asprone D, Fenu L, Prota A (2015) Experimental characterization of Italian composite adobe bricks reinforced with straw fibers. Compos Struct. https://doi.org/http://dx.doi.org/10.1016/j.compstruct.2014.11.060

20. SENSICO (2017) Reglamento Nacional de Edificaciones. Norma Técnica de Edificación NTE 0.80 Diseño y construcción con tierra reforzada. Servicio Nacional de Capacitación para la Industrial de la Construcción, Lima, Peru

21. ASTM (2017) D2845-08 - Standard Test Method for Laboratory Determination of Pulse Velocities and Ultrasonic Elastic Constants of Rock. United States

22. AENOR (2005) UNE-EN 14579:2005 - Métodos de ensayo para piedra natural. Determinación de la velocidad de propagación del sónido. Madrid, Spain

23. AENOR (2006) UNE-EN 12504-4:2006 - Ensayos de hormigón en estructuras. Parte 4: Determinación de la velocidad de los impulsos ultrasónicos. Madrid, Spain 